\title{
Inactivation of Infectious Bacteria Using Nonthermal Biocompatible Plasma Cabinet Sterilizer
}

\author{
Mahmuda Akter ${ }^{1,2,+}$, Dharmendra Kumar Yadav ${ }^{3,+}+\mathbb{D}$, Se Hoon $\mathrm{Ki}^{2,4} \oplus^{(}$, Eun Ha Choi ${ }^{1,2,4, *(\mathbb{C})}$ \\ and Ihn Han $1,2, *$ (iD \\ 1 Department of Plasma Bio-Display, Kwangwoon University, Seoul 01897, Korea; nipa21stfeb@gmail.com \\ 2 Plasma Bioscience Research Center, Applied Plasma Medicine Center, Kwangwoon University, Seoul 01897, \\ Korea; ksh8721@naver.com \\ 3 Department of Pharmacy, College of Pharmacy, Gachon University of Medicine and Science, \\ Incheon City 21924, Korea; dharmendra30oct@gmail.com \\ 4 Department of Electronic and Biological Physics, Kwangwoon University, Seoul 01897, Korea \\ * Correspondence: ehchoi@kw.ac.kr (E.H.C.); hanihn@kw.ac.kr (I.H.) \\ + These authors contributed equally to this work.
}

Received: 24 September 2020; Accepted: 30 October 2020; Published: 6 November 2020

\begin{abstract}
Nonthermal, biocompatible plasma (NBP) is a promising unique state of matter that is effective against a wide range of pathogenic microorganisms. This study focused on a sterilization method for bacteria that used the dielectric barrier discharge (DBD) biocompatible plasma cabinet sterilizer as an ozone generator. Reactive oxygen species play a key role in inactivation when air or other oxygen-containing gases are used. Compared with the untreated control, Escherichia coli (E. coli), Staphylococcus aureus (S. aureus), and Salmonella typhimurium (sepsis) were inhibited by approximately $99 \%$, or were nondetectable following plasma treatment. Two kinds of plasma sterilizers containing six- or three-chamber cabinets were evaluated. There was no noticeable difference between the two configurations in the inactivation of microorganisms. Both cabinet configurations were shown to be able to reduce microbes dramatically, i.e., to the nondetectable range. Therefore, our data indicate that the biocompatible plasma cabinet sterilizer may prove to be an appropriate alternative sterilization procedure.
\end{abstract}

Keywords: Nonthermal biocompatible plasma (NBP); cabinet sterilizer; Escherichia coli (E. coli); Staphylococcus aureus (S. aureus); Salmonella typhimurium (sepsis); Reactive oxygen species (ROS); Reactive nitrogen species (RNS)

\section{Introduction}

The use of physical means, such as atmospheric pressure plasmas, to sterilize surfaces and environments containing pathogenic microorganisms has received considerable attention in the past decades. Sterilization is defined as the total inactivation of all forms of living microorganisms and their spores. There are several drawbacks to sterilizing therapeutic devices in hospitals using conventional methods, such as wet/dry heat, chemical gases, or irradiation; for example, these approaches may affect the physical and biological performance of the therapeutic device [1], leading to material failure [2]. For successful disinfection, new approaches are required to eliminate infectious diseases. Nonthermal atmospheric pressure plasma technology is a promising potential sterilization method for the treatment of infectious diseases; notably, it does not suffer from the disadvantages of conventional methods $[3,4]$. 
Plasma technologies can serve as surface remedies and environmental sterilization approaches. ROS and RNS are produced by plasma, and can combine and destroy the cell surface of bacteria. Several studies have stated that reactive oxygen species play a main function in the inactivation of microbes, while other components generated by plasma (e.g., UV photons, electric fields, charged particles, and heat) make a small contribution [5,6]. NBP has been implemented for cancer treatments [7,8], sterilized viruses, bacteria, and mold [7,9], wound-healing therapies [10,11], etc. Recently, these approaches have been studied for food sterilization and plasma medicine [12-14]. Plasma also inactivates an extensive range of microbes through cellular-deadly reactive species [15-17]. Furthermore, the inactivation capability may be changed using different working gases, from which completely different types or amounts of reactive species could be generated [18-20]. Plasma-generated and the actuated arrangement of localized ROS within the gas and fluid stages consisting of atomic oxygen $(\mathrm{O})$, singlet oxygen $\left(\mathrm{O}_{2}\right)$, ozone $\left(\mathrm{O}_{3}\right)$, hydroxyl radicals $(\bullet \mathrm{OH})$, hydrogen peroxide $\left(\mathrm{H}_{2} \mathrm{O}_{2}\right)$ may destroy the bacterial structure through different pathways [21-24]. Inactivation was accomplished with diverse plasma sources such as a plasma jet, dielectric barrier discharge (DBD), microwave discharge, corona discharges, and plasma coverage [4]. Ehlbeck et al. studied the effect of plasma on the growth of approximately 20 forms of gram-positive and -negative pathogenic microbes. Other studies on microbial sterilization using nonthermal atmospheric plasma have been conducted worldwide [12,25-28]. Several research groups have established the inactivation of endospores [29,30], and many groups have presented effective microbial sterilization by atmospheric pressure plasma [31,32].

In this study, we report on the sterilization effect of a plasma cabinet sterilizer on Escherichia coli, staphylococcus aureus, and Salmonella typhimurium. These strains were selected as they are well-characterized gram-negative and -positive microbes that are utilized as model bacteria owing to their speedy growth rates. There are many reviews on the use of plasmas in sterilization applications; such a body of research is usually a prerequisite for the application of a sterilization procedure, as defined in global standards [32].

\section{Results}

\subsection{Physical Characterization and RONS Generation of DBD Plasma Cabinet Sterilizer}

Figure 1a shows a schematic configuration of the three-chamber cabinet system at atmospheric pressure under an air gas flow. The nonthermal plasma cabinet used in this experiment was made by Plasma Bioscience Research Center and Dawoo Korea (details in Materials and Methods Section). Typical waveforms of the current and voltage discharge created in the DBD plasma cabinet are shown in Figure 1b. As shown in Table 1, the electric discharge current was $\sim 13.01 \mathrm{~mA}$ for Irms at a frequency of $27.6 \mathrm{kHz}$ with a Vrms voltage of $4.16 \mathrm{kV}$.

Table 1. Physical parameters and conditions of the nonthermal DBD plasma device.

\begin{tabular}{cc}
\hline Parameters & Conditions \\
\hline Voltage $\left(\mathrm{V}_{\mathrm{rms}}, \mathrm{kV}\right)$ & 4.16 \\
\hline Current $\left(\mathrm{I}_{\mathrm{rms},} \mathrm{mA}\right)$ & 13.01 \\
\hline Period $(\mu \mathrm{s})$ & 36.20 \\
\hline Frequency $(\mathrm{kHz})$ & 27.6 \\
\hline Energy $($ Duty $)(\mathrm{J} / \mathrm{sec})$ & 0.24 \\
\hline
\end{tabular}


(a)
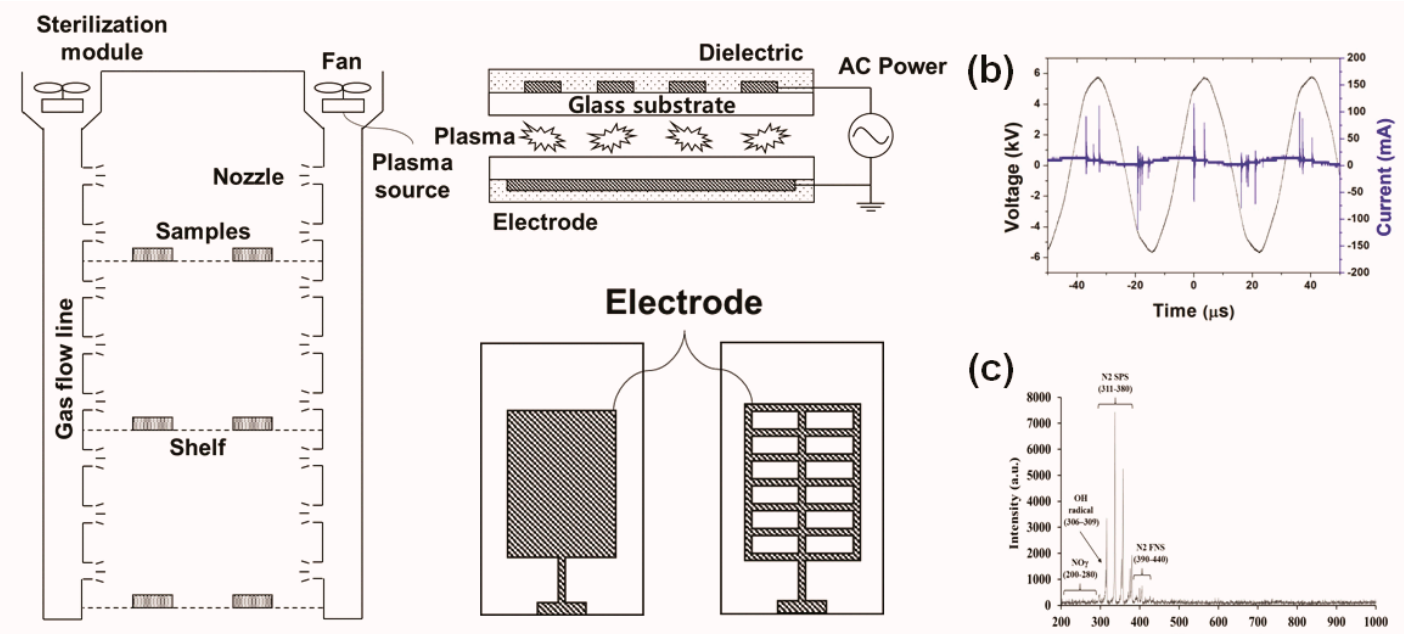

(c)

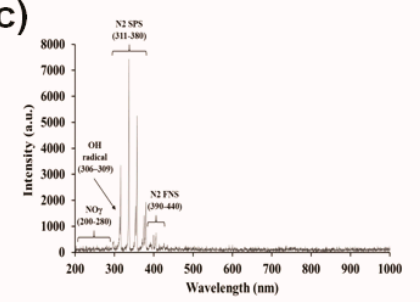

(d)

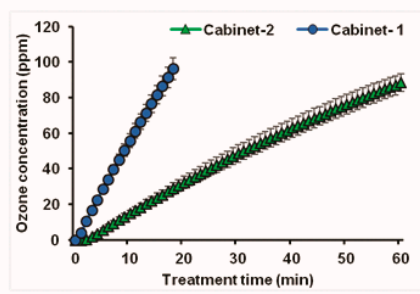

(e)

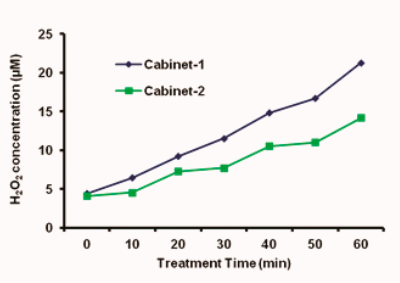

(f)

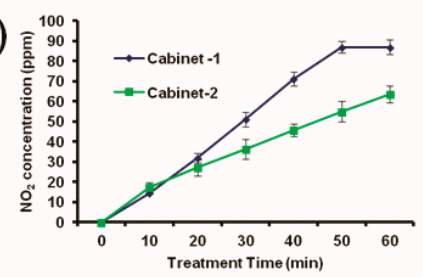

(g)
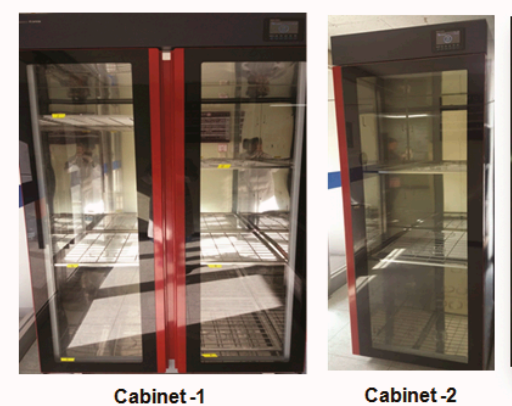

Cabinet -2

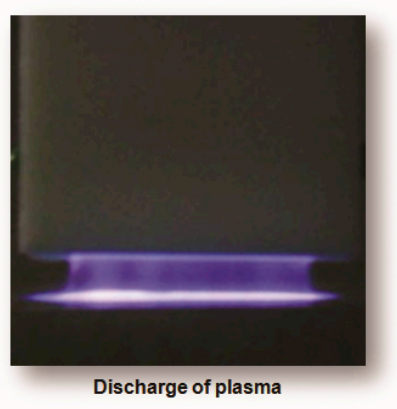

Figure 1. (a) Schematic of the experimental setup with the DBD nonthermal biocompatible plasma electrode structure; (b) current and voltage waveforms during discharge; (c) optical emission spectra (OES) of plasma; (d) ozone concentration measurement during treatment time; (e) the amount of $\mathrm{H}_{2} \mathrm{O}_{2}$; and (f) $\mathrm{NO}_{2}$ concentration according to plasma treatment time. (g) Photograph of the plasma cabinet sterilizer with six and three chambers and the discharge photo of plasma.

To measure the reactive oxygen or nitrogen species formed by the plasma, the optical emission spectrum (OES) was measured between 200 and $1000 \mathrm{~nm}$ from the plasma source. The intensity of the light emitted from the device was recorded with respect to the wavelength. The OES of the DBD plasma cabinet device used in this experiment showed that the $\mathrm{N}_{2}$ s positive system (SPS) lines were the predominant peaks in the near-UV region $(310-380 \mathrm{~nm})$. OH radicals $(306-309 \mathrm{~nm}), \mathrm{N}_{2}$ first negative system (FNS) (390-440 nm), and NO $\gamma(200-280 \mathrm{~nm})$ were also detected weakly in the OES spectrum shown in Figure 1c. 
The optical emission spectrum of the DBD plasma emission lines corresponded to $\mathrm{N}_{2}$, atomic nitrogen, and hydroxyl radicals. The emission bands produced by the radiative transition of the second positive and first negative systems of the excitation molecular nitrogen were observed between 310 and $440 \mathrm{~nm}$. These OES results explain the ozone generation in Figure 1d; ozone was generated according to the following equation.

$$
\begin{gathered}
\mathrm{N}_{2}+e \rightarrow \mathrm{N}_{2}^{+}+e \\
\mathrm{~N}_{2}^{+}+\mathrm{O}_{2} \rightarrow \mathrm{N}_{2}+2 \mathrm{O} \\
\mathrm{N}_{2}^{+}+\mathrm{O}_{2} \rightarrow \mathrm{N}_{2} \mathrm{O}+\mathrm{O} \\
\mathrm{O}+\mathrm{O}_{2}+\mathrm{M} \rightarrow \mathrm{O}_{3}+\mathrm{M} \\
\mathrm{OH}+\mathrm{OH} \cdot \rightarrow \mathrm{H}_{2} \mathrm{O}_{2}
\end{gathered}
$$

The ozone produced by the plasma is recognized as a reactive species having a sterilizing effect on microbes [33]. As the amounts of $\mathrm{O}_{3}, \mathrm{H}_{2} \mathrm{O}_{2}$, and $\mathrm{NO}_{2}$ are known to be modulated by different treatments, we calculated their generated quantities for the different treatment conditions. Figure $1 \mathrm{~d}$ shows that when plasma was treated for $10 \mathrm{~min}$, the ozone concentration was about $14.8 \mathrm{ppm}$ for the three-chamber (cabinet 2) plasma cabinet, but for $10 \mathrm{~min}$ of treatment in the six-chamber (cabinet 1) cabinet, the ozone concentration was $55.7 \mathrm{ppm}$. For the six-chamber cabinet (cabinet 1) after $20 \mathrm{~min}$ of treatment, the ozone concentration increased sharply and exceeded the maximum limit of $100 \mathrm{ppm}$ of the ozone meter. For the three-chamber cabinet (cabinet 2), the ozone concentration was approximately 100 ppm after 60 min of treatment. Figure 1 e shows the concentrations of $\mathrm{H}_{2} \mathrm{O}_{2}$ generated according to the plasma processing time. $\mathrm{H}_{2} \mathrm{O}_{2}$ is generated as shown in Equation (5). The $\mathrm{H}_{2} \mathrm{O}_{2}$ concentration continuously increased in both cabinets according to the treatment time. After $60 \mathrm{~min}$ of plasma treatment, the $\mathrm{H}_{2} \mathrm{O}_{2}$ concentration was $21.28 \mu \mathrm{M}$ in cabinet 1 and $14.15 \mu \mathrm{M}$ in cabinet 2 . Figure $1 \mathrm{f}$ shows that the $\mathrm{NO}_{2}$ concentration also increased in both cabinets according to the treatment conditions. However, both cabinets were shown to be able to significantly change bactericidal activity despite the variations in the levels of ozone, $\mathrm{H}_{2} \mathrm{O}_{2}$, and $\mathrm{NO}_{2}$. Therefore, RONS was shown to play a key role in creating oxidative effects from the plasma. Figure $1 \mathrm{~g}$ shows the experimental cabinet sterilizer and discharge photo of plasma used in this study.

\subsection{Effect of Six Chambers (Cabinet 1) Plasma Cabinet Treatment on Inactivation of Bacteria}

In this experiment, the goal was to sterilize a therapeutic device. The antibacterial effect of the plasma cabinet sterilizer was evaluated at an optimized temperature, considering the potential effect of low stress and temperature within the cabinet on bacterial viability. To determine the inactivation of E. coli and S. aureus after plasma sterilization, a conventional cfu counting method involving an agar plate was used (Figure 2) to indicate bacterial culturability. In comparison to the untreated control test, the treated groups exhibited significant deactivation of both bacteria. Specifically, plasma exposure inhibited bacteria growth by almost $99 \%$ at concentrations of $1 \times 10^{6}$ and $1 \times 10^{7} \mathrm{cfu} \cdot \mathrm{ml}^{-1}$; however, for $E$ coli, a reduction of $100 \%$ was obtained for $1 \times 10^{8} \mathrm{cfu} \cdot \mathrm{mL}^{-1}$ (Figure 2) compared to the control. The mean log reduction obtained for both species at a $10^{4-6}$ dilution was plotted to acquire the nondetectable levels of bacteria. For both species, at a $10^{6}$ dilution, the log reduction was almost zero $\mathrm{cfu} / \mathrm{mL}$ or nondetectable in the plasma cabinet sterilizer treatment group compared to the control. The error bars for the mean graphs were calculated and plotted based on the standard deviation. Table 2 shows the percentage of inhibition of metabolically active $E$. coli increased from $99.6 \pm 0.1 \%$ to $99.8 \pm 0.1 \%$ and that of $S$. aureus from $98.9 \pm 0.1$ to $99.8 \pm 0.1$, or to a nondetectable degree. The rates of inhibition with metabolic capability exhibited upward trends for each microorganism. 
E. coli

(a)

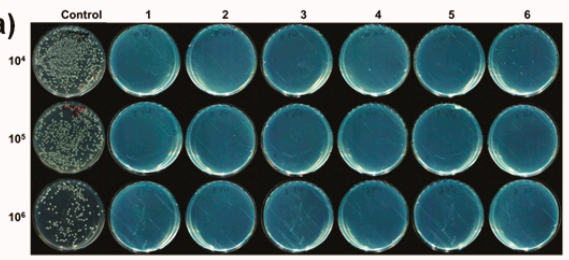

(c)
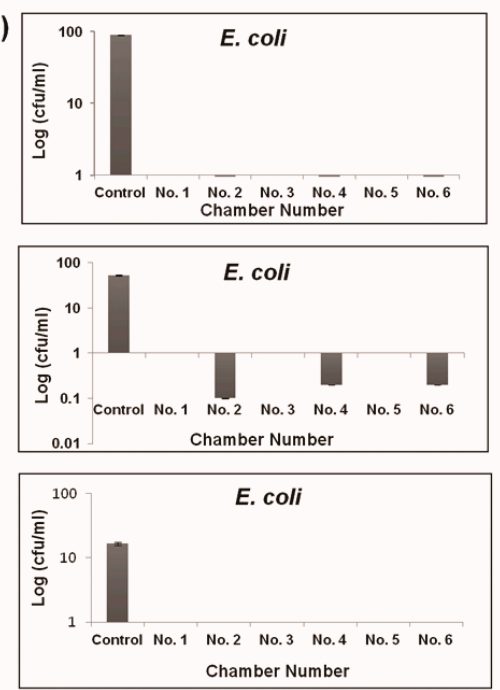

S. aureus

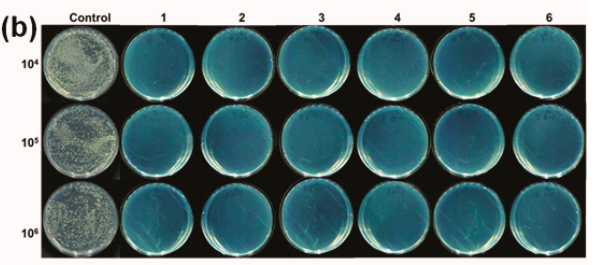

(d) 1000 S. aureus
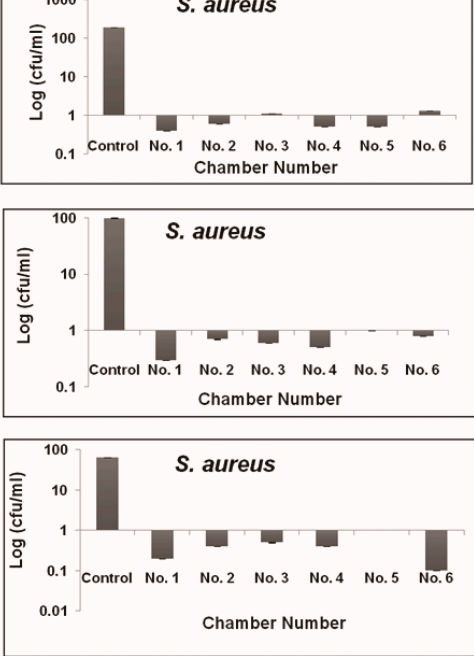

Figure 2. Plasma inactivation efficiency of Escherichia coli (E. coli) and Staphylococcus aureus (S. aureus) in the six-chamber (cabinet 1 ) cabinet $(\mathbf{a}, \mathbf{b})$. Representative culture plates with cultures at $10^{4}, 10^{5}$, and $10^{6}$ dilution factors. (c,d) Growth characteristics curve. All $t$-test value is $p<0.001$ as compared to control.

Table 2. Inhibition percentage in six-chamber plasma cabinet treatment compared with control. (ND: Nondetected).

\begin{tabular}{|c|c|c|c|c|c|}
\hline Species & Chamber & Inhibition \% & Species & Chamber & Inhibition \% \\
\hline \multirow{7}{*}{$\begin{array}{c}\text { E. coli } \\
\left.\text { (Dilution } 10^{4}\right)\end{array}$} & Control & 0 & \multirow{7}{*}{$\begin{array}{c}\text { S. aureus } \\
\text { (Dilution } 10^{4} \text { ) }\end{array}$} & Control & 0 \\
\hline & No. 1 & ND & & No. 1 & $99.8 \pm 0.1$ \\
\hline & No. 2 & $99.8 \pm 0.1$ & & No. 2 & $99.7 \pm 0.1$ \\
\hline & No. 3 & ND & & No. 3 & $99.4 \pm 0.1$ \\
\hline & No. 4 & $99.8 \pm 0.1$ & & No. 4 & $99.7 \pm 0.1$ \\
\hline & No. 5 & ND & & No. 5 & $99.7 \pm 0.1$ \\
\hline & No. 6 & $98.9 \pm 0.2$ & & No. 6 & $99.3 \pm 0.1$ \\
\hline \multirow{7}{*}{$\begin{array}{c}\text { E. coli } \\
\left(\text { Dilution } 10^{5}\right)\end{array}$} & Control & 0 & \multirow{7}{*}{$\begin{array}{c}\text { S. aureus } \\
\text { (Dilution } 10^{5} \text { ) }\end{array}$} & Control & 0 \\
\hline & No.1 & ND & & No. 1 & $99.7 \pm 0.1$ \\
\hline & No. 2 & $99.8 \pm 0.1$ & & No. 2 & $99.3 \pm 0.1$ \\
\hline & No. 3 & ND & & No. 3 & $99.4 \pm 0.2$ \\
\hline & No. 4 & $99.6 \pm 0.1$ & & No. 4 & $99.5 \pm 0.1$ \\
\hline & No. 5 & ND & & No. 5 & $98.9 \pm 0.1$ \\
\hline & No. 6 & $99.6 \pm 0.1$ & & No. 6 & $99.2 \pm 0.2$ \\
\hline \multirow{7}{*}{$\begin{array}{c}\text { E. coli } \\
\text { (Dilution } 10^{6} \text { ) }\end{array}$} & Control & 0 & \multirow{7}{*}{$\begin{array}{c}\text { S. aureus } \\
\text { (Dilution } 10^{6} \text { ) }\end{array}$} & Control & 0 \\
\hline & No. 1 & ND & & No. 1 & $99.7 \pm 0.1$ \\
\hline & No. 2 & ND & & No. 2 & $99.4 \pm 0.1$ \\
\hline & No. 3 & ND & & No. 3 & $99.2 \pm 0.1$ \\
\hline & No. 4 & ND & & No. 4 & $99.4 \pm 0.1$ \\
\hline & No. 5 & ND & & No. 5 & ND \\
\hline & No. 6 & ND & & No. 6 & $99.8 \pm 0.1$ \\
\hline
\end{tabular}




\subsection{Effect of Three-Chamber (cabinet 2) Plasma Cabinet Treatment on the Inactivation of Bacteria}

The efficacy of the three-chamber plasma cabinet in inactivating E. coli and S. aureus is shown in Figure 3 and (Table 3). For the three-chamber cabinet, the E. coli and S. aureus bacterial populations were nondetectable in $1 \times 10^{8} \mathrm{cfu} \cdot \mathrm{mL}^{-1}$ (Table 3). The log reduction was almost zero $\mathrm{cfu} / \mathrm{mL}$ or nondetectable in the $10^{6}$ dilutions. The concentrations of each of the bacterial species were observed until they were nondetectable by plate count. It is evident from the table that the population intensity of the bacterial test for the plasma treatment group was reduced for the two microorganisms compared with the control. The difference between the treatment and control groups was significant $(p<0.001)$. The error bars for the mean graphs were measured in the same way as with the six chambers. The inhibition percentage of metabolically active E. coli increased from $97.9 \pm 0.1 \%$ to $99.8 \pm 0.1 \%$ and S. aureus from $97.1 \pm 0.1$ to $99.6 \pm 0.1$ or to nondetectable degree, as shown in Table 3 . The toxicity of the Salmonella typhimurium (sepsis) bacterial inactivation by the cabinet is also shown in the agar plate (Figure S1). As there was no significant difference between the two cabinets, we tested Salmonella typhimurium only in the three-chamber cabinet. After plasma treatment, the cfu/mL was less than 10 , or was $99.9 \%$ inhibited, whereas the control was $1.11 \times 10^{4}$.
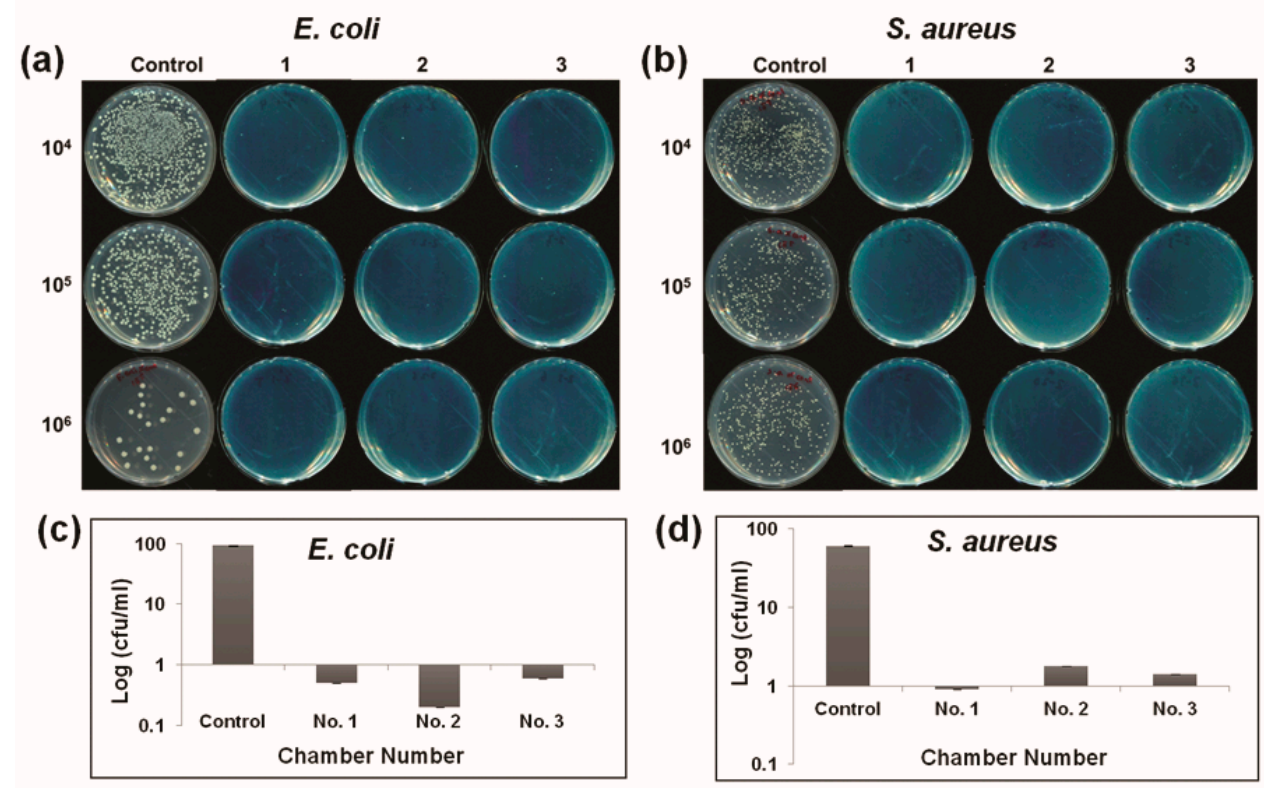

(d)
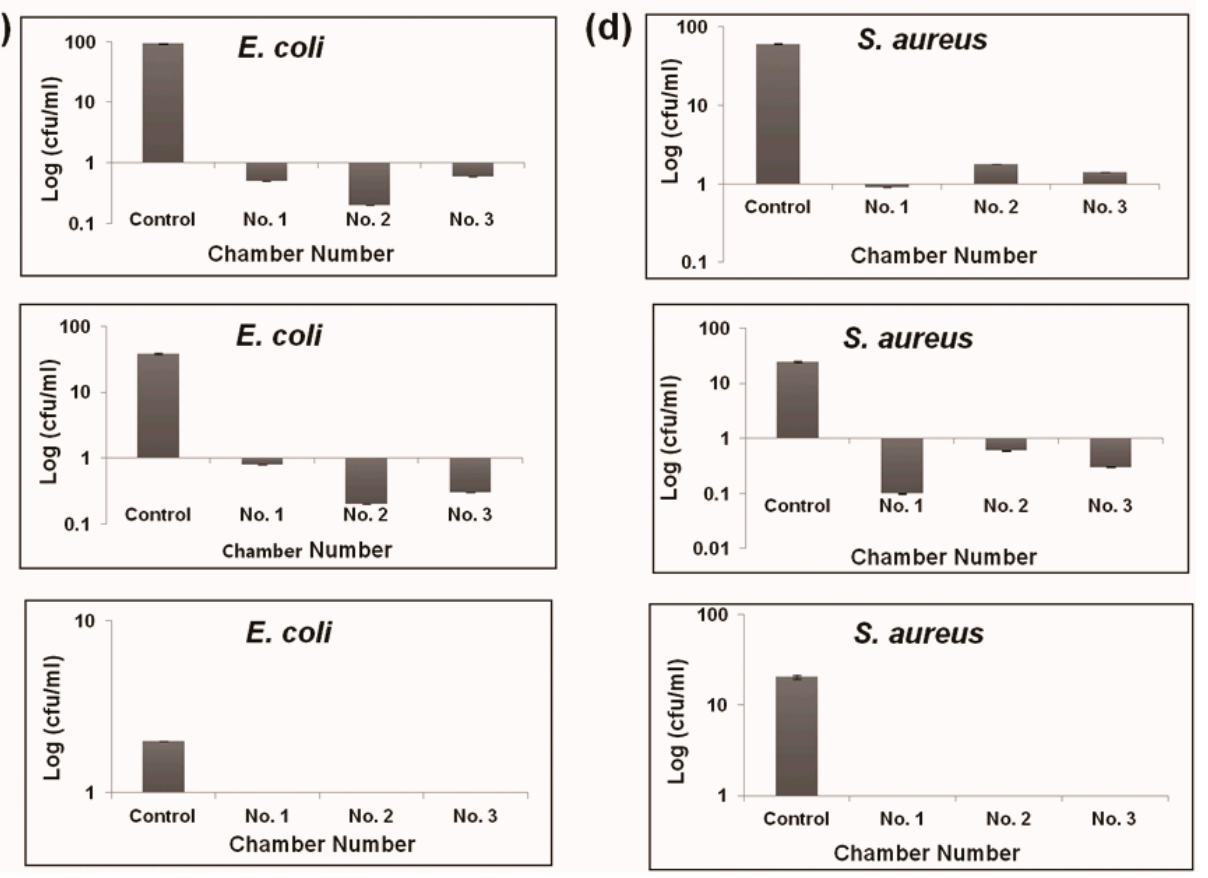

Figure 3. (a,b) Representative culture plates showing the inactivation efficiency of Escherichia coli (E. coli) and Staphylococcus aureus (S. aureus) at $10^{4}, 10^{5}$, and $10^{6}$ dilution factors. (c,d) Growth characteristics curve for the bacteria in the three chambers (cabinet 2 ) of the plasma cabinet. All $t$-test value is $p<0.001$ as compared to control. 
Table 3. Percentage of inhibition after three-chamber plasma cabinet treatment compared with control. (ND: Nondetected).

\begin{tabular}{|c|c|c|c|c|c|}
\hline Species & Chamber & Inhibition \% & Species & Chamber & Inhibition $\%$ \\
\hline \multirow{4}{*}{$\begin{array}{c}\text { E. coli } \\
\left(\text { Dilution } 10^{4}\right)\end{array}$} & Control & 0 & \multirow{4}{*}{$\begin{array}{c}\text { S. aureus } \\
\text { (Dilution } 10^{4} \text { ) }\end{array}$} & Control & 0 \\
\hline & No. 1 & $99.5 \pm 0.1$ & & No. 1 & $98.5 \pm 0.1$ \\
\hline & No. 2 & $99.8 \pm 0.1$ & & No. 2 & $97.1 \pm 0.1$ \\
\hline & No. 3 & $99.4 \pm 0.1$ & & No. 3 & $97.7 \pm 0.1$ \\
\hline \multirow{4}{*}{$\begin{array}{c}\text { E. coli } \\
\left.\text { (Dilution } 10^{5}\right)\end{array}$} & Control & 0 & \multirow{4}{*}{$\begin{array}{c}\text { S. aureus } \\
\text { (Dilution } 10^{5} \text { ) }\end{array}$} & Control & 0 \\
\hline & No. 1 & $97.9 \pm 0.1$ & & No. 1 & $99.6 \pm 0.1$ \\
\hline & No. 2 & $99.5 \pm 0.1$ & & No. 2 & $97.6 \pm 0.1$ \\
\hline & No. 3 & $99.2 \pm 0.1$ & & No. 3 & $98.8 \pm 0.1$ \\
\hline \multirow{4}{*}{$\begin{array}{c}\text { E. coli } \\
\left(\text { Dilution } 10^{6}\right)\end{array}$} & Control & 0 & \multirow{4}{*}{$\begin{array}{c}\text { S. aureus } \\
\text { (Dilution } 10^{6} \text { ) }\end{array}$} & Control & 0 \\
\hline & No. 1 & ND & & No. 1 & ND \\
\hline & No. 2 & ND & & No. 2 & ND \\
\hline & No. 3 & ND & & No. 3 & ND \\
\hline
\end{tabular}

\subsection{In Silico Study}

To assess the stability and reliability underlying the molecular interactions, top docked poses were considered for analysis. The docking results for $\mathrm{H}_{2} \mathrm{O}_{2}$ against $E$. coli (PDB ID: 4PRV) showed a high binding affinity docking score, i.e., -6.512 (Figure $4 \mathrm{a}$ ), and the formation of six H-bonds to the acidic, (polar, negative charged), e.g., Glu-50 (glutamic acid); positively charged, e.g., Arg4 (arginine); and aromatic (hydrophobic), e.g., Tyr-109 (tyrosine), which are involved in the binding of ROS/RNS and may modulate the function of the protein. Similarly, the docking results of ozone showed high binding affinity, i.e., -6.428 (Figure 4 b), and revealed seven H-bonds with hydrophobic amino acid residue, that is, Gly-117 (glycine), Ala-100 (alanine), Ile-94 (isoleucine) and nucleophilic (polar, hydrophobic), that is, SER-10, SER-121 (serine) bound to the protein. Likewise, the nitrates also showed good binding affinity, i.e., -4.562 and three H-bonds with hydrophobic, that is, Gly-117 (glycine) and Lys-103 (lysine); therefore, $\mathrm{H}_{2} \mathrm{O}_{2}$ showed strong hydrophobic interaction with E. coli, which led to more stability and activity in these molecules (Figure $4 \mathrm{c}$ ).

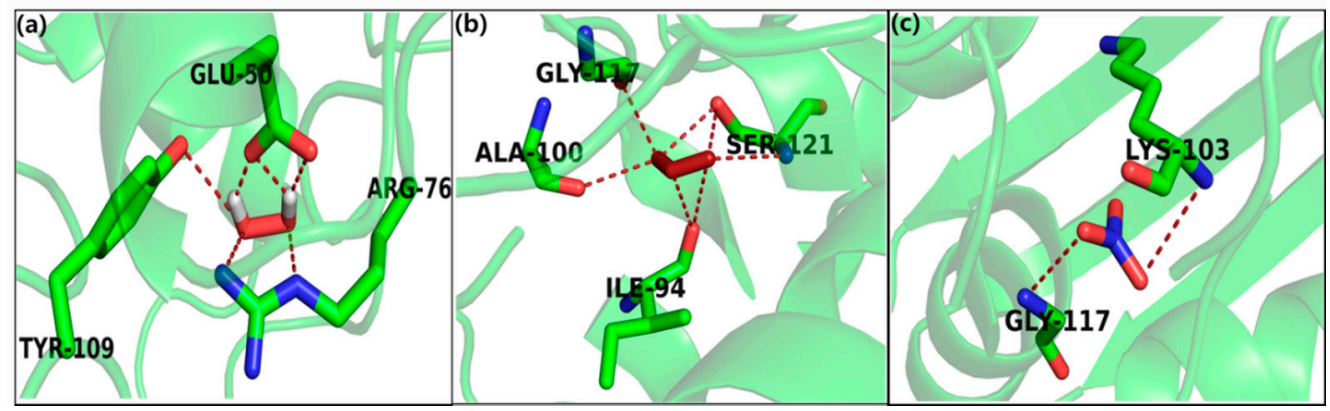

Figure 4. Molecular docking interaction of docked (a) hydrogen peroxide, (b) ozone, and (c) nitrates with E. coli.

On the other hand, the docking results of $\mathrm{H}_{2} \mathrm{O}_{2}$ against the $S$. aureus target protein showed high binding affinity, as indicated by a docking score of -5.7584 (Figure $5 \mathrm{a}$ ) and the formation of five H-bonds to the hydrophobic, that is, Val-203 (valine); polar amide chemical nature due to Asn-208 (asparagines) and basic (polar, hydrophobic and positive charged), that is, Leu-200, Leu-209 (leucine) within a $3 \AA$ radius. Similarly, the docking results for ozone showed high binding affinity, i.e., -5.384 (Figure $5 b$ ) and the three H-bonds with hydrophobic polar amide chemical nature due to Asn-263 (asparagines); 
hydrophobic that is, Val-203 (valine) and basic (polar, hydrophobic and positive charged), that is, Leu-209 bound to the protein. Likewise, the nitrates showed low binding affinity -2.15 without any h-bond interaction (Figure 5c).

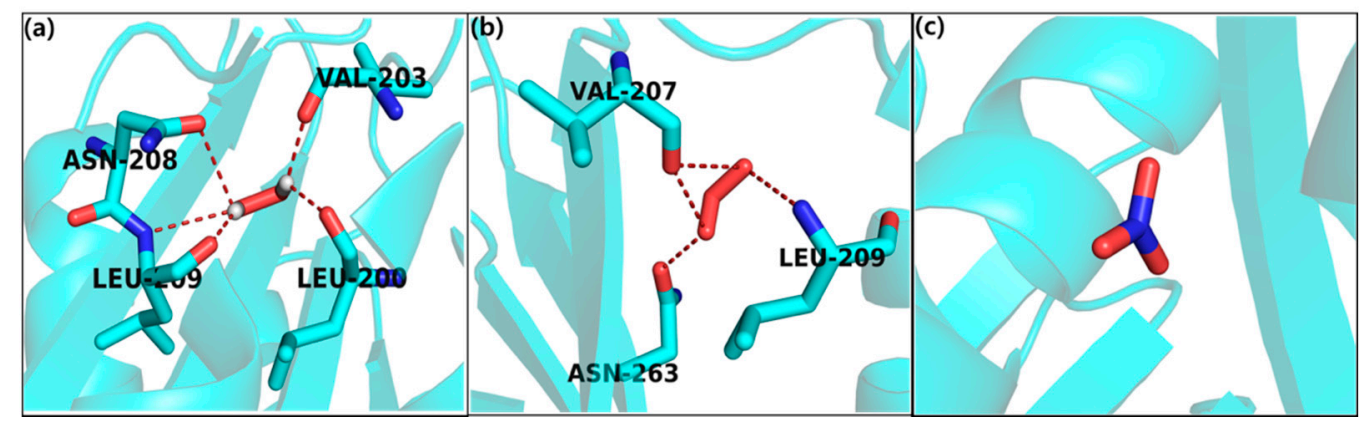

Figure 5. Molecular docking interaction of docked (a) hydrogen peroxide, (b) ozone, and (c) nitrates with S. aureus.

To further support the above observations, molecular docking studies of hydrogen peroxide, ozone, and nitrates were carried out by exploring the binding site interacting residues. For the docking study, we used a modeled secondary structure, i.e., S. typhimurium, which was dominated with an alpha helix $(57.94 \%)$, followed by random coils $(30.29 \%)$ and extended strands $(8.24 \%)$. The details are provided in Supplementary Table S1. Likewise, the docking results for $\mathrm{H}_{2} \mathrm{O}_{2}$ against $S$. typhimurium showed a high binding affinity docking score, i.e., -5.72 (Figure 6a), and the formation of two H-bonds to the nucleophilic (polar, hydrophobic), for example, Thr108 (Threonine) and hydrophobic, for example, Leu-319 (Leucine) were bound to the protein. Model of S. typhimurium indicates $82.4 \%$ of the residues in the most favourable region, $13.4 \%$ in the allowed region, $1.3 \%$ in the generously allowed region and $2.9 \%$ in the disallowed region (Supplementary Figures S2 and S3).

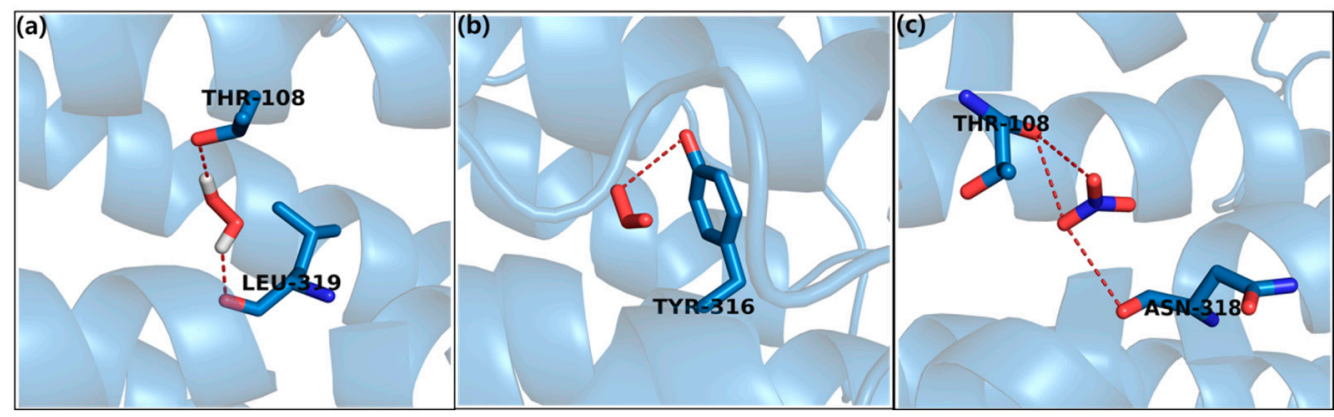

Figure 6. Molecular docking interaction of docked (a) hydrogen peroxide, (b) ozone, and (c) nitrates with Salmonella typhimurium.

Similarly, the docking results of ozone showed high binding affinity, i.e., -5.52 (Figure $6 \mathrm{~b}$ ), and a H-bond with nucleophilic (polar, hydrophobic) for example, Thr108. Finally, the nitrates also showed good binding affinity, i.e., -5.94 (Figure 6c), and the formation of three H-bonds with nucleophilic (polar, hydrophobic) for example, Thr108 and polar amide type, for example, Asn318 (Asparagine); were bound to the protein. Therefore, $\mathrm{H}_{2} \mathrm{O}_{2}$, ozone, and nitrates showed strong hydrophobic interactions with S. typhimurium, leading to more stability and activity in these molecules.

The simulation study revealed that hydrogen peroxide, ozone, and nitrates showed strong H-bonding and high binding affinity with pathogenic strains E. coli, S. aureus, and Salmonella typhimurium. Only ozone showed a low binding affinity with $S$. aureus. This fact indicates more potential inhibitory activity against the E. coli, S. aureus and Salmonella typhimurium. Hence, this approach represents a remarkable milestone in increasing the utility of NBP for plasma medicines. 


\section{Discussion}

In this study, sterilization processes for controlling the development of E. coli, S. aureus, and Salmonella typhimurium (sepsis) were performed. From the inactivation efficacy results, it was shown that plasma has a strong effect on plate count; the inhibition percentage results demonstrated that it reduced bacterial cell counts to nondetectable levels (Figures 2 and 3, and Tables 2 and 3). This may be due to oxidative pressure due to the reactive species produced by the plasma. Reactive oxygen species can create oxidative stress in cells. In our previous work [34,35], it was reported that ROS and RNS can affect the membranes of cells and microorganisms. During plasma treatment, the generated reactive oxygen species, which are associated with the process and structure parameters, attacked both the cellular envelope and intracellular components.

The atmospheric air plasma creates ROS and RNS species, including hydrogen peroxide, ozone, and nitrates, which are among the foremost commonly identified species utilizing the dielectric barrier discharge (DBD) system [36]. The oxidative damage of macromolecules like DNA, proteins, and lipids by reactive species created by plasma has an inhibitory impact on bacterial populations [37]. Interactions between plasma species and bacteria have already been reported [36].

The majority of plasma sterilizers produce ozone, which can oxidize the cell walls of micro-organisms; then, the plasma cocktail leads to an increase in cell membrane permeability and cell death. This plasma cabinet produces of a variety of different free radicals such as hydroxyl radicals, singlet oxygen, hydrogen peroxide, etc., and not only ozone. The device produces NO and NOx, as well as a small amount of UV. These excited nitrogen molecules can combine with oxygen molecules to form secondary reactive radicals which are effective in damaging the cell membranes. In particular, the device produces hydrogen peroxide gas molecules $\left(\mathrm{H}_{2} \mathrm{O}_{2}\right)$ which decompose into a plasma state, generating hydroxyl radicals. These are powerful oxidizing agents, which are effective against the cell membranes of microbes. Hydrogen peroxide gas breaks down into water and oxygen after sterilization.

The antimicrobial effects of our nonthermal plasma sterilizer have been successfully demonstrated on different microorganisms. The present study revealed that pathogenic strains can be effectively eradicated using a plasma cabinet. The results obtained for the plasma cabinet sterilizer show that both six- and three-chamber cabinets were effective in inhibiting both pathogenic strains. There was no clear difference in the impact it had on the gram-negative (e.g., E. coli, Salmonella typhimurium (sepsis) and -positive (e.g., S. aureus) bacteria in either cabinet. It was found that the three bacterial strains were sensitive to the plasma cabinet sterilizer based on large and clear growth-inhibition percentages, which suggests that plasma can be used to eradicate a wide range of both gram-positive and -negative bacteria (Tables 2 and 3). Plasma technology is used in various fields including semiconductors, materials, and agriculture. Plasma-treated carboxymethyl cellulose-coated polypropylene (PP/CMC) films and materials can serve as food antimicrobial packaging [38]. Recent developments, e.g., platforms of nanoparticles, have been used to increase the effect of pharmaceutical formulations for wound healing and functionalized with diverse antimicrobial compounds [39]. Nhan et al. studied the chemical composition of the essential oil extracted from leaves to assess their potential antimicrobial, antitrichomonas and antiviral activities [40]. Overall, the obtained results suggested that the plasma cabinet sterilizer has a high degree of antimicrobial activity against both gram-positive and -negative bacteria. These results also provide fundamental insights into the mechanisms of plasma species interacting with bacteria and into plasma sterilization in general.

\section{Materials and Methods}

\subsection{Bacterial Strains and Maintenance of Culture}

Escherichia. coli, Staphylococcus aureus, and Salmonella typhimurium strain were used for this study. The strains were selected to represent both gram-negative and -positive bacteria. The strains were obtained from the Korean Collection for Type Cultures (КСTC). The strains were maintained as frozen 
stocks at $-80^{\circ} \mathrm{C}$ in an appropriate medium supplemented with $50 \%$ glycerol. Each bacterial strain was streaked onto luria bertani agar (LB agar, Agar Bacteriological, MB-A1651, MB cell) and incubated at $37^{\circ} \mathrm{C}$ for $24 \mathrm{~h}$. The bacterial culture plates were then maintained at $4{ }^{\circ} \mathrm{C}$.

\subsection{Preparation of Bacterial Cell Suspension}

Cells were grown overnight by inoculating isolated colonies of bacteria in luria bertani medium (LB Broth High Salt, MB-L4488, MB cell) at $37^{\circ} \mathrm{C}$ on a rotary shaker at a constant speed of $200 \mathrm{rpm}$. We estimated cell density using readings of optical density (OD) measurements. Bacterial cells were adjusted to $10^{7}$ colony forming units per $\mathrm{mL}(\mathrm{cfu} / \mathrm{mL}$ ) by optical density measurement at $600 \mathrm{~nm}$ (OD600, BioPhotometry, Eppendorf, Hamburg, Germany). A total of $20 \mu \mathrm{L}$ of the overnight bacterial cultures were placed in a sterile empty petri dish and kept in the clean bench for 15-20 min to dry completely. We divided $20 \mu \mathrm{L}$ of 10 drops into $2-\mu \mathrm{L}$ drops for early drying. Then, the bacteria cultures were placed in the plasma cabinet for treatment $(50-70 \mathrm{~min})$. These estimates were validated using cfu measurements of the serially diluted cells.

\subsection{Experimental Cabinet Sterilizer and Plasma Generation in Cabinet}

The size of the six- and three-chamber cabinet was $1960(\mathrm{H}) \times 1100(\mathrm{~W}) \times 750(\mathrm{D})$ and $1960(\mathrm{H}) \times$ $680(\mathrm{~W}) \times 750$ (D). A dielectric barrier discharge (DBD) plasma system was used. The plasma device was placed in the upper part of the chamber, and the produced RONS passed through the gas flow region into the chamber. As shown in Figure 1a, the structure of the electrode for DBD plasma was composed of a pair of parallel plate electrodes. Six-micrometer thick electrodes were printed on a glass substrate of $0.7 \mathrm{~mm}$ using silver attach screen printing. Following drying, $\mathrm{SiO}_{2}$ dielectric with 70-100 $\mu \mathrm{m}$ thickness was printed on the substrate and dried. A lattice pattern was used for the top electrode, and flat one for the bottom electrode. The gap distance between the two electrodes was $1.0 \mathrm{~mm}$. The voltages and currents of the electrodes were measured using a GWINSTEK oscilloscope with a $1000 \times$ voltage probe (P6015A, Tektronix) and a current probe (P6021A, Tektronix). Optical emission spectra (OES) were measured using a spectrometer (HR4000, Ocean Optics). The atmospheric air was used to generate plasma. Samples were placed in different chambers and exposed to plasma for $50 \mathrm{~min}$ and $20 \mathrm{~min}$, resting to remove the ozone using a charcoal filter. Plasma was exposed for $50 \mathrm{~min}$ because the air had to achieve an equilibrium state. After the plasma cabinet treatment, the samples were diluted in $10 \mathrm{~mL} \mathrm{LB}$ media and subsequently kept in the rotary shaker for $3 \mathrm{~h}$. Finally, the residual live bacteria and spores were counted. Tests were performed in copy and triplicate. The bacterial suspension with no plasma treatment was reserved as a negative control in a rotary shaker for $3 \mathrm{~h}$.

\subsection{Measurement of Reactive Oxygen and Nitrogen Species (RONS)}

We determined the amounts of ozone, hydrogen peroxide, and $\mathrm{NO}_{2}$ species in different treatment conditions of the DBD plasma cabinet. An ozone meter (SKT-9300, 0.1 to $100 \mathrm{ppm}$, resolution $0.1 \mathrm{ppm}$ ) was used to measure the concentration of ozone. Hydrogen peroxide was chemically quantified by a commercially available reagent (QuantiChrom TM, Peroxide Assay Kit, DIOX-250, $585 \mathrm{~nm}$ ). $\mathrm{NO}_{2}$ was detected using a $\mathrm{NO}_{2}$ detector (GASTiger2000, 0 to $100 \mathrm{ppm}$, resolution $0.01 \mathrm{ppm}$ ).

\subsection{Colony-Forming unit Analysis}

A colony-forming unit (cfu) is used to quantify viable microorganisms; the results are provided as $\mathrm{cfu} / \mathrm{mL}$ for each plate. Bacterial development was determined by counting colony growth on the agar plates (standard plate count). To examine the bacterial development, the concentrations of the cells $(\mathrm{cfu} / \mathrm{mL})$ were determined using the plate counting method [41]. In this technique, appropriate serial dilutions of the microbial cells were utilized to inoculate LB agar plates. The inoculated plates were then incubated at $37^{\circ} \mathrm{C}$ for $24 \mathrm{~h}$. By checking the number of colonies created after incubation and multiplying them with the dilution factor, the number of cells in the primary population was determined as $\mathrm{cfu} / \mathrm{mL}$. A total of $0.1 \mathrm{~mL}$ of the series of dilutions was pipetted onto agar plates utilizing 
the spread plate technique. After the surfaces of the agar plates were dry, the plates were incubated at $37^{\circ} \mathrm{C}$ for $24 \mathrm{~h}$. All the plates that contained 20 to 300 colonies were identified and the colonies on the entire plate were counted per $\mathrm{ml}$.

\subsection{In Silico Study}

To explore the bioactive sites of ROS and RNS species, including hydrogen peroxide, ozone, and nitrates with amino acids of E. coli and S. aureus, the AutoDock Vina [42] interface was used for molecular docking. The ROS/RNS species (hydrogen peroxide, ozone, and nitrates) were automatically docked into the binding pocket of a target protein using the Lamarckian genetic algorithm, empirically producing a scoring function. The X-ray crystallographic structures of E. coli and S. aureus (PDB: 4PRV) [43] and (PDB: 3VOB) [44] protein receptor were taken from the protein data bank and further modified for docking calculations. The accuracy of AutoDock in the prediction of ligand confirmation was assured using the redocking procedure explained in [44,45]. One hundred docking poses for each inhibitor were calculated. Kollman united atom partial charges, AutoDock atom types, and polar only hydrogen atoms were taken into account while preparing the protein $[46,47]$.

\subsection{Statistical Analysis}

All tests were repeated a minimum of three times, and the statistical significance of the difference between the mean values was determined through a standard error evaluation. The results are represented as means \pm SD. Statistics from the bacterial development studies were compared using the student t-test, and $p<0.05$ was used as the significance level [48].

\section{Conclusions}

The plasma cabinet sterilizer therapy represents a new antimicrobial technology for the sterilization of pathogenic microorganisms. The air DBD plasma had significant antimicrobial effects on both the gram-negative and -positive microbes in both cabinets. Our data revealed that plasma cabinet treatment is highly effective at inactivating E. coli., S. aureus, and Salmonella typhimurium (sepsis). RONS played a key role in the presence of oxidative effects from the plasma, leading to the deterioration of bacterial structures and their mediated features. Therefore, DBD plasma might be a powerful device for the eradication of infectious bacteria. Further study will determine the action on molecular and cellular levels regarding the sterilization/disinfection mechanisms of bacteria.

Supplementary Materials: The following are available online at http://www.mdpi.com/1422-0067/21/21/8321/s1. Figure S1: Representative Salmonella typhimurium (sepsis) growth characteristics on an agar plate. No viable colonies were observed after the plasma cabinet treatment (cabinet 2). Figure S2: 3D Structure of S. typhimurium modelled through I-TASSER server. Helices are represented in red, sheets in gray and loops in green. Figure S3: Ramachandran plot for validation of S. typhimurium. Table S1: Details of secondary structure elements of S. typhimurium.

Author Contributions: Conceptualization: I.H.; Data curation: I.H., M.A. and S.H.K.; Funding acquisition: I.H.; Investigation: M.A. and D.K.Y.; In silico study: D.K.Y.; Project administration: I.H.; Writing—original draft: M.A. and D.K.Y.; Writing—review \& editing: I.H., M.A.; Administrative, technical, or material support (i.e., reporting or organizing data, constructing databases): I.H., E.H.C.; Study supervision: I.H., E.H.C. All authors have read and agreed to the published version of the manuscript.

Funding: This work was supported by the Leading Foreign Research Institute Recruitment Program through the National Research Foundation of Korea (NRF- 2016K1A4A3914113) funded by the Ministry of Science, ICT of the Korean Government. It was supported by Basic Science Research Program through the National Research Foundation of Korea (NRF) funded by the Ministry of Education (2020R1I1A1A01073071).

Conflicts of Interest: There is no conflict of interest. 


\section{References}

1. Matthews, I.P.; Gibson, C.; Samuel, A.H. Sterilisation of implantable devices. Clin. Mater. 1994, 15, $191-215$. [CrossRef]

2. Athanasiou, K.A.; Niederauer, G.G.; Agrawal, C.M. Sterilization, toxicity, biocompatibility and clinical applications of polylactic acid/polyglycolic acid copolymers. Biomaterials 1996, 17, 93-102. [CrossRef]

3. Rezaei, F.; Vanraes, P.; Nikiforov, A.; Morent, R.; De Geyter, N. Applications of plasma-liquid systems: A review. Materials 2019, 12, 2751. [CrossRef] [PubMed]

4. Ehlbeck, J.; Schnabel, U.; Polak, M.; Winter, J.; von Woedtke, T.; Brandenburg, R.; von dem Hagen, T.; Weltmann, K.-D. Low temperature atmospheric pressure plasma sources for microbial decontamination. J. Phys. D Appl. Phys. 2011, 44, 013002. [CrossRef]

5. Zhang, Q.; Sun, P.; Feng, H.; Wang, R.; Liang, Y.; Zhu, W.; Becker, K.H.; Zhang, J.; Fang, J. Assessment of the roles of various inactivation agents in an argon-based direct current atmospheric pressure cold plasma jet. J. Appl. Phys. 2012, 111, 123305. [CrossRef]

6. Deng, X.; Shi, J.; Kong, M.G. Physical Mechanisms of Inactivation of Bacillus subtilis Spores Using Cold Atmospheric Plasmas. IEEE Trans. Plasma Sci. 2006, 34, 1310-1316. [CrossRef]

7. Graves, D.B. The emerging role of reactive oxygen and nitrogen species in redox biology and some implications for plasma applications to medicine and biology. J. Phys. D Appl. Phys. 2012, 45, 263001. [CrossRef]

8. Ishaq, M.; Evans, M.M.; Ostrikov, K.K. Effect of atmospheric gas plasmas on cancer cell signaling. Int. J. Cancer 2014, 134, 1517-1528. [CrossRef] [PubMed]

9. Belgacem, B.Z.; Carré, G.; Charpentier, E.; Le-Bras, F.; Maho, T.; Robert, E.; Pouvesle, J.-M.; Polidor, F.; Gangloff, S.C.; Boudifa, M.; et al. Innovative non-thermal plasma disinfection process inside sealed bags: Assessment of bactericidal and sporicidal effectiveness in regard to current sterilization norms. PLoS ONE 2017, 12, e0180183. [CrossRef] [PubMed]

10. Lee, O.J.; Ju, H.W.; Khang, G.; Sun, P.P.; Rivera, J.; Cho, J.H.; Park, S.J.; Eden, J.G.; Park, C.H. An experimental burn wound-healing study of non-thermal atmospheric pressure microplasma jet arrays. J. Tissue Eng. Regen. Med. 2016, 10, 348-357. [CrossRef] [PubMed]

11. Kang, S.U.; Choi, J.W.; Chang, J.W.; Kim, K.; Kim, Y.S.; Park, J.K.; Kim, Y.E.; Lee, Y.S.; Yang, S.S.; Kim, C.H. N2 non-thermal atmospheric pressure plasma promotes wound healing in vitro and in vivo: Potential modulation of adhesion molecules and matrix metalloproteinase-9. Exp. Dermatol. 2017, 26, 163-170. [CrossRef]

12. Misra, N.N.; Tiwari, B.K.; Raghavarao, K.S.M.S.; Cullen, P.J. Nonthermal Plasma Inactivation of Food-Borne Pathogens. Food Eng. Rev. 2011, 3, 159-170. [CrossRef]

13. Sensenig, R.; Kalghatgi, S.; Cerchar, E.; Fridman, G.; Shereshevsky, A.; Torabi, B.; Arjunan, K.P.; Podolsky, E.; Fridman, A.; Friedman, G.; et al. RETRACTED ARTICLE: Non-thermal Plasma Induces Apoptosis in Melanoma Cells via Production of Intracellular Reactive Oxygen Species. Ann. Biomed. Eng. 2011, 39, 674-687. [CrossRef] [PubMed]

14. Cullen, P.J.; Milosavljevi, V. Spectroscopic characterization of a radio-frequency argon plasma jet discharge in ambient air. Prog. Theor. Exp. Phys. 2015, 2015, 63. [CrossRef]

15. Kayes, M.M.; Critzer, F.J.; Kelly-Wintenberg, K.; Roth, J.R.; Montie, T.C.; Golden, D.A. Inactivation of Foodborne Pathogens Using A One Atmosphere Uniform Glow Discharge Plasma. Foodborne Pathog. Dis. 2007, 4, 50-59. [CrossRef]

16. Basaran, P.; Basaran-Akgul, N.; Oksuz, L. Elimination of Aspergillus parasiticus from nut surface with low pressure cold plasma (LPCP) treatment. Food Microbiol. 2008, 25, 626-632. [CrossRef] [PubMed]

17. Klämpfl, T.G.; Isbary, G.; Shimizu, T.; Li, Y.-F.; Zimmermann, J.L.; Stolz, W.; Schlegel, J.; Morfill, G.E.; Schmidt, H.-U. Cold Atmospheric Air Plasma Sterilization against Spores and Other Microorganisms of Clinical Interest. Appl. Environ. Microbiol. 2012, 78, 5077-5082. [CrossRef]

18. Savas, S.; Ersoy, A.; Gulmez, Y.; Kilic, S.; Levent, B.; Altintas, Z. Nanoparticle Enhanced Antibody and DNA Biosensors for Sensitive Detection of Salmonella. Materials 2018, 11, 1541. [CrossRef]

19. Purevdorj, D.; Igura, N.; Ariyada, O.; Hayakawa, I. Effect of feed gas composition of gas discharge plasmas on Bacillus pumilus spore mortality. Lett. Appl. Microbiol. 2003, 37, 31-34. [CrossRef] 
20. Zhang, M.; Oh, J.K.; Cisneros-Zevallos, L.; Akbulut, M. Bactericidal effects of nonthermal low-pressure oxygen plasma on S. typhimurium LT2 attached to fresh produce surfaces. J. Food Eng. 2013, 119, 425-432. [CrossRef]

21. Machala, Z.; Tarabova, B.; Hensel, K.; Spetlikova, E.; Sikurova, L.; Lukes, P. Formation of ROS and RNS in water electro-sprayed through transient spark discharge in air and their bactericidal effects. Plasma Process. Polym. 2013, 10, 649-659. [CrossRef]

22. Lukes, P.; Dolezalova, E.; Sisrova, I.; Clupek, M. Aqueous-phase chemistry and bactericidal effects from an air discharge plasma in contact with water: Evidence for the formation of peroxynitrite through a pseudo-second-order post-discharge reaction of $\mathrm{H} 2 \mathrm{O} 2$ and HNO2. Plasma Sources Sci. Technol. 2014, 23, 015019. [CrossRef]

23. Lu, X.; Naidis, G.V.; Laroussi, M.; Reuter, S.; Graves, D.B.; Ostrikov, K. Reactive species in non-equilibrium atmospheric-pressure plasmas: Generation, transport, and biological effects. Phys. Rep. 2016, 630, 1-84. [CrossRef]

24. Machala, Z.; Chládeková, L.; Pelach, M. Plasma agents in bio-decontamination by dc discharges in atmospheric air. J. Phys. D Appl. Phys. 2010, 43, 222001. [CrossRef]

25. Josh Smith, U.K.E. Chemistry for Antimicrobial Properties of Water Treated With Non-Equilibrium Plasma. J. Nanomed. Biother. Discov. 2014, 4, 1-5. [CrossRef]

26. Niemira, B.A.; Sites, J. Cold Plasma Inactivates Salmonella Stanley and Escherichia coli O157:H7 Inoculated on Golden Delicious Apples. J. Food Prot. 2016, 71, 1357-1365. [CrossRef]

27. Niemira, B.A. Cold Plasma Decontamination of Foods. Annu. Rev. Food Sci. Technol. 2012, 3, $125-142$. [CrossRef]

28. Ulbin-Figlewicz, N.; Jarmoluk, A.; Marycz, K. Antimicrobial activity of low-pressure plasma treatment against selected foodborne bacteria and meat microbiota. Ann. Microbiol. 2015, 65, 1537-1546. [CrossRef]

29. Shimizu, S.; Barczyk, S.; Rettberg, P.; Shimizu, T.; Klaempfl, T.; Zimmermann, J.L.; Hoeschen, T.; Linsmeier, C.; Weber, P.; Morfill, G.E.; et al. Cold atmospheric plasma-A new technology for spacecraft component decontamination. Planet. Space Sci. 2014, 90, 60-71. [CrossRef]

30. Stapelmann, K.; Fiebrandt, M.; Raguse, M.; Awakowicz, P.; Reitz, G.; Moeller, R. Utilization of low-pressure plasma to inactivate bacterial spores on stainless steel screws. Astrobiology 2013, 13, 597-606. [CrossRef] [PubMed]

31. Timmermann, E.; Prehn, F.; Schmidt, M.; Höft, H.; Brandenburg, R.; Kettlitz, M. Indoor air purification by dielectric barrier discharge combined with ionic wind: Physical and microbiological investigations. J. Phys. D Appl. Phys. 2018, 51, 164003. [CrossRef]

32. British Standards. Sterilization of Health Care Products-Dry Heat-Requirements for the Development, Validation and Routine Control of a Sterilizion Process for Medical Devices; British Standards: London, UK, 2013.

33. Fernández, A.; Noriega, E.; Thompson, A. Inactivation of Salmonella enterica serovar Typhimurium on fresh produce by cold atmospheric gas plasma technology. Food Microbiol. 2013, 33, 24-29. [CrossRef]

34. Ki, S.H.; Masur, K.; Baik, K.Y.; Choi, E.H. Effects of humidity on room disinfection by dielectric barrier discharge plasma. J. Phys. D Appl. Phys. 2019, 52, 425204. [CrossRef]

35. Akter, M.; Jangra, A.; Choi, S.A.; Choi, E.H.; Han, I. Non-Thermal Atmospheric Pressure Bio-Compatible Plasma Stimulates Apoptosis via p38/MAPK Mechanism in U87 Malignant Glioblastoma. Cancers 2020, 12, 245. [CrossRef]

36. Cheng, X.; Meng, B.; Chen, X.; Han, M.; Chen, H.; Su, Z.; Shi, M.; Zhang, H. Single-Step Fluorocarbon Plasma Treatment-Induced Wrinkle Structure for High-Performance Triboelectric Nanogenerator. Small 2016, 12, 229-236. [CrossRef]

37. Bourke, P.; Ziuzina, D.; Han, L.; Cullen, P.J.; Gilmore, B.F. Microbiological interactions with cold plasma. J. Appl. Microbiol. 2017, 123, 308-324. [CrossRef]

38. Honarvar, Z.; Farhoodi, M.; Khani, M.R.; Mohammadi, A.; Shokri, B.; Ferdowsi, R.; Shojaee-Aliabadi, S. Application of cold plasma to develop carboxymethyl cellulose-coated polypropylene films containing essential oil. Carbohydr. Polym. 2017, 176, 1-10. [CrossRef]

39. Negut, I.; Grumezescu, V.; Grumezescu, A. Treatment Strategies for Infected Wounds. Molecules 2018, 23, 2392. [CrossRef] [PubMed] 
40. Le, N.T.; Ho, D.V.; Doan, T.Q.; Le, A.T.; Raal, A.; Usai, D.; Madeddu, S.; Marchetti, M.; Usai, M.; Rappelli, P.; et al. In Vitro Antimicrobial Activity of Essential Oil Extracted from Leaves of Leoheo domatiophorus Chaowasku, DT Ngo and HT Le in Vietnam. Plants 2020, 9, 453.

41. Demicheli, M.C.; Goes, A.M.; de Andrade, A.S.R. Ultrastructural changes in Paracoccidioides brasiliensis yeast cells attenuated by gamma irradiation. Mycoses 2007, 50, 397-402. [CrossRef]

42. Baez-Santos, Y.M.; Mielech, A.M.; Deng, X.; Baker, S.; Mesecar, A.D. Catalytic Function and Substrate Specificity of the Papain-Like Protease Domain of nsp3 from the Middle East Respiratory Syndrome Coronavirus. J. Virol. 2014, 88, 12511-12527. [CrossRef] [PubMed]

43. Fang, Y.; Lu, Y.; Zang, X.; Wu, T.; Qi, X.; Pan, S.; Xu, X. 3D-QSAR and docking studies of flavonoids as potent Escherichia coli inhibitors. Sci. Rep. 2016, 6, 23634. [CrossRef]

44. Ballu, S.; Itteboina, R.; Sivan, S.K.; Manga, V. Structural insights of Staphylococcus aureus FtsZ inhibitors through molecular docking, 3D-QSAR and molecular dynamics simulations. J. Recept. Signal Transduct. 2018, 38, 61-70. [CrossRef] [PubMed]

45. Yadav, D.; Dhawan, S.; Chauhan, A.; Qidwai, T.; Sharma, P.; Bhakuni, R.; Dhawan, O.; Khan, F. QSAR and Docking Based Semi-Synthesis and In Vivo Evaluation of Artemisinin Derivatives for Antimalarial Activity. Curr. Drug Targets 2014, 15, 753-761. [CrossRef]

46. Yadav, D.K.; Ahmad, I.; Shukla, A.; Khan, F.; Negi, A.S.; Gupta, A. QSAR and docking studies on chalcone derivatives for antitubercular activity against M.tuberculosis H37Rv. J. Chemom. 2014, 28, 499-507. [CrossRef]

47. Dwivedi, G.R.; Maurya, A.; Yadav, D.K.; Singh, V.; Khan, F.; Gupta, M.K.; Singh, M.; Darokar, M.P.; Srivastava, S.K. Synergy of clavine alkaloid 'chanoclavine' with tetracycline against multi-drug-resistant E. coli. J. Biomol. Struct. Dyn. 2019, 37, 1307-1325. [CrossRef]

48. Justo, O.R.; Pérez, V.H.; Alvarez, D.C.; Alegre, R.M. Growth of Escherichia coli Under Extremely Low-Frequency Electromagnetic Fields. Appl. Biochem. Biotechnol. 2006, 134, 155-164. [CrossRef]

Publisher's Note: MDPI stays neutral with regard to jurisdictional claims in published maps and institutional affiliations. 